\title{
Platelet depletion and aspirin treatment protect mice in a two-event model of transfusion-related acute lung injury
}

\author{
Mark R. Looney, ${ }^{1,2,3}$ John X. Nguyen, ${ }^{3}$ Yongmei Hu, ${ }^{2}$ \\ Jessica A. Van Ziffle, ${ }^{2}$ Clifford A. Lowell, ${ }^{2}$ and Michael A. Matthay 1,3 \\ ${ }^{1}$ Department of Medicine, ${ }^{2}$ Department of Laboratory Medicine, and ${ }^{3}$ Cardiovascular Research Institute, UCSF, San Francisco, California, USA.
}

\begin{abstract}
Transfusion-related acute lung injury (TRALI) is the leading cause of transfusion-associated mortality in the US. Previously, we established an immune-mediated TRALI mouse model, wherein mice with cognate antigen were challenged with $\mathrm{MHC}$ class I $\mathrm{mAb}$. In this study, when mice housed in a rodent, specific pathogen-free barrier room were challenged with MHC I $\mathrm{mAb}$, there was significant protection from TRALI compared with nonbarrier mice. Priming mice with LPS restored lung injury with $\mathrm{mAb}$ challenge. Using TLR4-deficient bone marrow chimeras, the priming phenotype was restricted to animals with WT hematopoietic cells, and depletion of either neutrophils or platelets was protective. Both neutrophils and platelets were sequestered in the lungs of mice with TRALI, and retention of platelets was neutrophil dependent. Interestingly, treatment with aspirin prevented lung injury and mortality, but blocking the P selectin or CD11b/CD18 pathways did not. These data suggest a 2-step mechanism of TRALI: priming of hematopoietic cells, followed by vascular deposition of activated neutrophils and platelets that then mediate the severe lung injury. Furthermore, our data offer an explanation for the increased incidence of TRALI in patients with immune priming conditions, and we suggest what we believe to be a novel therapeutic approach.
\end{abstract}

\section{Introduction}

Transfusion-related acute lung injury (TRALI) is a major cause of morbidity after blood transfusion and is the leading cause of transfusion-associated mortality reported to the US FDA $(1,2)$. It has a reported incidence of 1 in 5,000 blood products transfused but is likely to be significantly more common due to under-recognition and underreporting (3).

TRALI most commonly develops when a patient is transfused with a blood donor product containing an anti-HLA or anti-neutrophil antibody that recognizes the cognate antigen in the recipient (4). We have previously reported the first mouse model of TRALI, which models the $\mathrm{Ab}$ theory by challenging $\mathrm{H} 2 \mathrm{~K}^{\mathrm{d}}+$ mice with matched $\mathrm{Ab}$ (5). This model produces severe lung endothelial damage, resulting from binding of the anti-MHC I mAb to vascular cells and recognition of the bound $\mathrm{Ab}$ by neutrophil $\mathrm{F} \mathrm{C} \gamma$ receptors, leading to leukocyte activation and tissue injury. While this model has helped describe the pathogenesis of acute lung injury (ALI) after blood transfusions, several clinically important questions remain unanswered.

The risk factors contributing to a TRALI event have been poorly characterized and can be broadly categorized into donor and recipient elements. The donor risk factors include high-volume plasma products (6), parity of the donor (7), and possibly specific Ab type (i.e., anti-HLA or anti-neutrophil Abs) (3) and Ab titer. Important risk factors in the recipient remain undefined, though certain patient populations seem to be at risk, including patients with active inflammation or infection, recent cardiopulmonary bypass, and chronic alcohol abuse (8-10). Indeed, there appears to be an increased incidence of ALI after blood product transfusion in patients in intensive care units, in which many patients have active infections and have had recent surgical procedures (8).

Conflict of interest: The authors have declared that no conflict of interest exists. Citation for this article: J. Clin. Invest. 119:3450-3461 (2009). doi:10.1172/JCI38432.
One of the main conundrums in understanding the pathogenesis of TRALI is why only a minority of patients transfused with a blood product containing a HLA or neutrophil Ab that matches the recipient's HLA or neutrophil antigen develop TRALI $(3,11$, 12). Immune priming factors in the transfused recipient could increase susceptibility in a multi-event or threshold model of TRALI (13). Experimentally, in an isolated, perfused lung model of TRALI, lung injury after challenge with plasma or lipids from stored human red blood cells (14) or platelets (15) was dependent on the priming of rats with LPS. An in vitro model of TRALI has also been reported in which priming of endothelial cells with LPS is necessary to produce barrier disruption (16). In addition, multiple experimental ALI models are routinely used that rely on 2 insults, such as ischemia/reperfusion (17) and either intratracheal (i.t.) LPS or acid and mechanical ventilation $(18,19)$. The latter of these models has also recently been reported to be dependent on the presence of platelets and platelet P selectin, specifically (20).

To better understand the pathogenesis of TRALI and to explore why an Ab-antigen match infrequently produces clinically evident ALI, we now report what we believe to be a new, 2-event model. Using this 2-event model, an immune cell priming step with LPS is a prerequisite for the lung injury development. We also report what we believe to be the novel finding that platelet-neutrophil interactions are critical to the development of TRALI in our model.

\section{Results}

Severity of experimental TRALI is significantly influenced by the animal housing environment. We have previously reported that BALB/c mice $\left(\mathrm{H} 2 \mathrm{~K}^{\mathrm{d}}\right)$ develop ALI when challenged with i.v. MHC I mAb $\left(\mathrm{H} 2 \mathrm{~K}^{\mathrm{d}}, 4.5 \mathrm{mg} / \mathrm{kg}\right)(5)$. The lung injury is severe, with only $50 \%$ survival to 2 hours. These experiments were performed using mice housed in nonbarrier, nonspecific pathogen-free rooms (referred to herein as nonbarrier mice). However, when similar experiments 
A
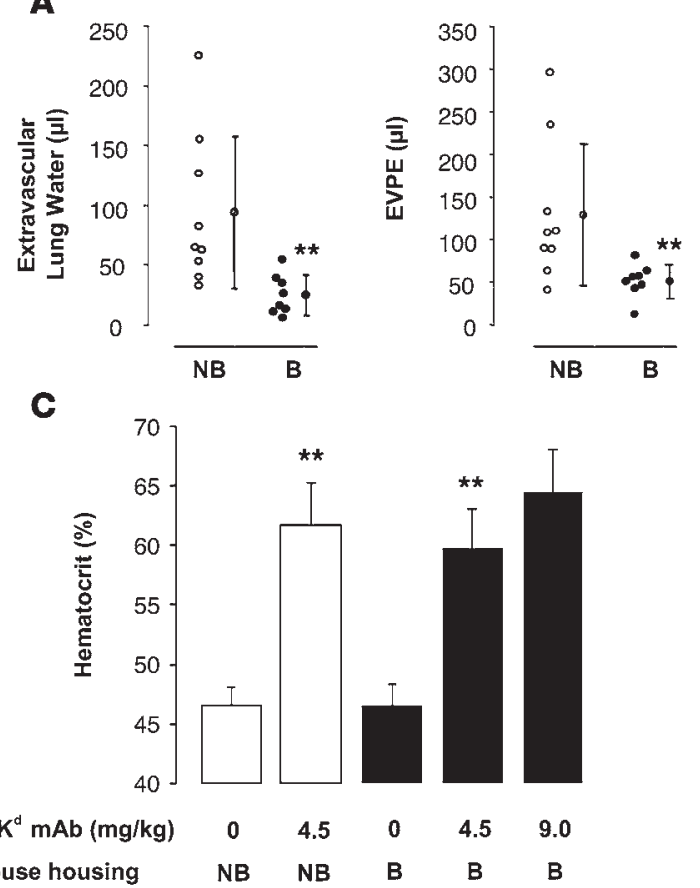

B
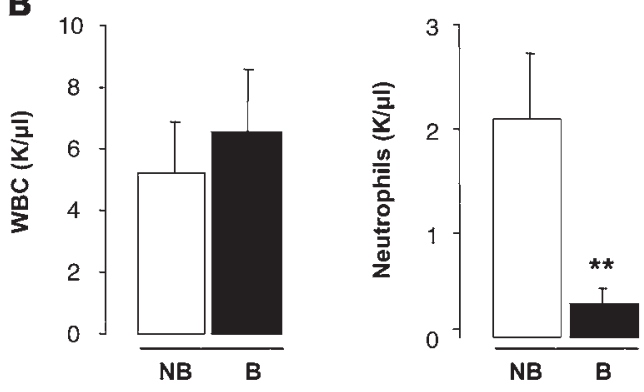

D

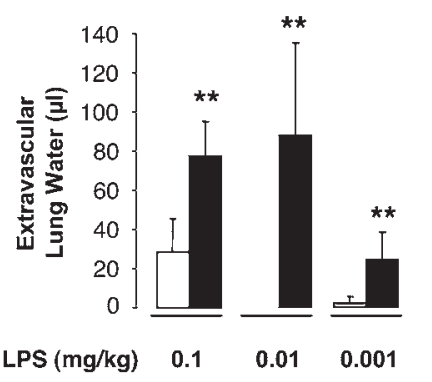

i.t. LPS (mg/kg) $\quad 0.1 \quad 0.01 \quad 0.001$

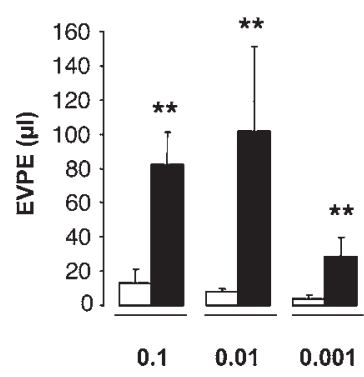

Figure 1

$\mathrm{BALB} / \mathrm{c}$ mice $\left(\mathrm{H}_{2} \mathrm{~K}^{\mathrm{d}}\right)$ housed in a barrier, specific pathogen-free room are protected from TRALI and have lower circulating neutrophils compared with that in nonbarrier animals. LPS i.t. restores lung injury in barrier animals. (A) Extravascular lung water and EVPEs measured 2 hours after injection of $\mathrm{MHC}$ I mAb (4.5 mg/kg, i.v.). Vertical lines indicate mean \pm SD. ${ }^{* \star} P<0.05$ barrier (B) vs. nonbarrier mice (NB). (B) Baseline peripheral white blood cell and neutrophil counts in nonbarrier and barrier mice. ${ }^{* *} P<0.05$ barrier vs. nonbarrier mice. (C) Hematocrit response 2 hours after MHC I $\mathrm{mAb} .{ }^{* \star} P<0.05$ nonbarrier mice and barrier mice with $\mathrm{MHC}$ I mAb $(4.5 \mathrm{mg} / \mathrm{kg})$ vs. mice with no Ab, respectively. (D) Extravascular lung water and EVPEs in barrier mice administered i.t. LPS (white bars) and i.t. LPS plus MHC I mAb ( $4.5 \mathrm{mg} / \mathrm{kg}$; black bars). ${ }^{\star *} P<0.05$ vs. LPS alone.

were performed on animals housed at the UCSF rodent, specific pathogen-free barrier facility (referred to herein as barrier mice), animals were resistant to lung injury induced by the anti-MHC I $\mathrm{mAb}$. We were surprised by the decreased accumulation of extravascular lung water and lung vascular permeability to protein in the animals housed in the barrier versus nonbarrier rooms (Figure 1A). While the total peripheral blood white blood cells counts were similar in the 2 groups, the barrier-housed mice had significantly lower neutrophil counts (Figure 1B).

The barrier mice challenged with MHC I mAb had similar evidence of plasma leak and hemoconcentration compared with the nonbarrier mice (Figure 1C), but the plasma leak was not targeted to the lung. Doubling the concentration of MHC I mAb produced a trend for more hemoconcentration (Figure 1C) but failed to increase lung injury (data not shown).

TRALI can be restored by priming mice with low-dose LPS. In response to the change in animal housing and subsequent lung injury in our model, we added an immune priming step using low-dose LPS. Mice were first challenged noninvasively with i.t. LPS at 3 concentrations (Figure 1D). The LPS was administered 24 hours prior to MHC I $\mathrm{mAb}$ challenge and produced minimal to no lung injury in isolation (white bars; Figure 1D). However, when combined with MHC I mAb (4.5 mg/kg, i.v.), the lung injury response was restored with 0.1 and $0.01 \mathrm{mg} / \mathrm{kg}$ LPS (black bars; Figure 1D).

The immune priming was even more robust when LPS was administered by the i.p. route. Low-dose LPS $(0.1 \mathrm{mg} / \mathrm{kg}$, i.p. $)$ produced no lung injury in isolation, but when combined with MHC I mAb, severe lung injury was observed with a plateau at $0.5-1.0 \mathrm{mg} / \mathrm{kg}$ of $\mathrm{mAb}$ (Figure 2, A and B). In fact, all animals challenged with $4.5 \mathrm{mg} / \mathrm{kg}$ of $\mathrm{mAb}$ died by 45 minutes after injection (Figure $2 \mathrm{C}$ ). Higher concentrations of $\mathrm{mAb}$ yielded a step-wise, dose-dependent increase in mortality (Figure 2C).

Mice administered i.p. LPS $(0.1 \mathrm{mg} / \mathrm{kg})$ (Figure 3B) had an increase in lung interstitial cellularity, but no evidence of ALI compared with normal mice (Figure 3A). However, mice challenged with both i.p. LPS and MHC I mAb $(1 \mathrm{mg} / \mathrm{kg})$ had severe lung edema (Figure 3C), often expiring with lung edema fluid extruding from the mouth and nose. Mice in the 2-event model had evidence of hemoconcentration at their death or at the 2 hour endpoint (Figure 3D). Mice administered i.t. LPS $(0.1 \mathrm{mg} / \mathrm{kg})$ had no evidence of lung injury until challenged with MHC I mAb (Supplemental Figure 1, A and B; supplemental material available online with this article; doi:10.1172/JCI38432DS1).

Low-dose LPS priming increases circulating neutrophils and sequesters neutrophils in the lungs. The addition of low-dose i.p. LPS to barrierhoused animals increased circulating neutrophil counts (Figure 4A) to a similar level as that for nonbarrier-housed mice (Figure 1B). When LPS-primed mice were challenged with MHC I mAb, peripheral blood neutropenia was observed (Figure 4A). Coincident with the rise in peripheral blood neutrophil counts, neutrophil sequestration in the lung microvasculature also occurred in i.p. LPS-primed mice (Figure 4C), when compared with that of controls (Figure 4B). When MHC I mAb was added, the lung neutrophil sequestration markedly increased (Figure 4D), reflecting the peripheral blood neutropenia observed (Figure 4A). While i.p. LPS priming produced intravascular neutrophil sequestration, i.t. LPS priming produced 
A

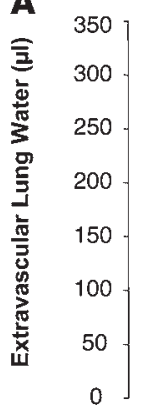

i.p. LPS $(0.1 \mathrm{mg} / \mathrm{kg}) \quad$ + $\mathrm{H} 2 \mathrm{~K}^{\mathrm{d}} \mathrm{mAb}(\mathrm{mg} / \mathrm{kg}) \quad 0$
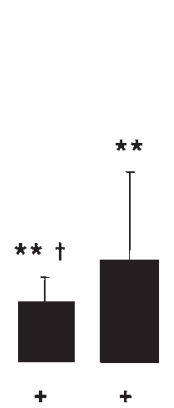

0.225

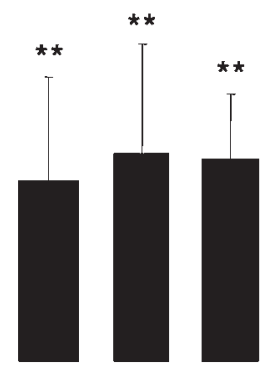

$+\quad+$

$\begin{array}{lll}1.0 & 2.25 \quad 4.5\end{array}$
B

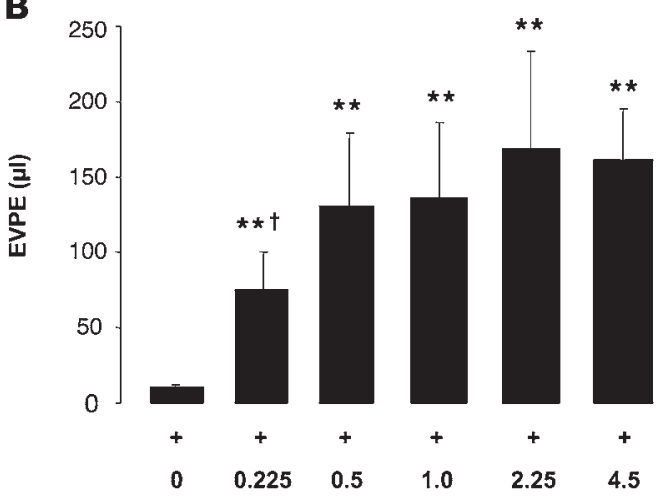

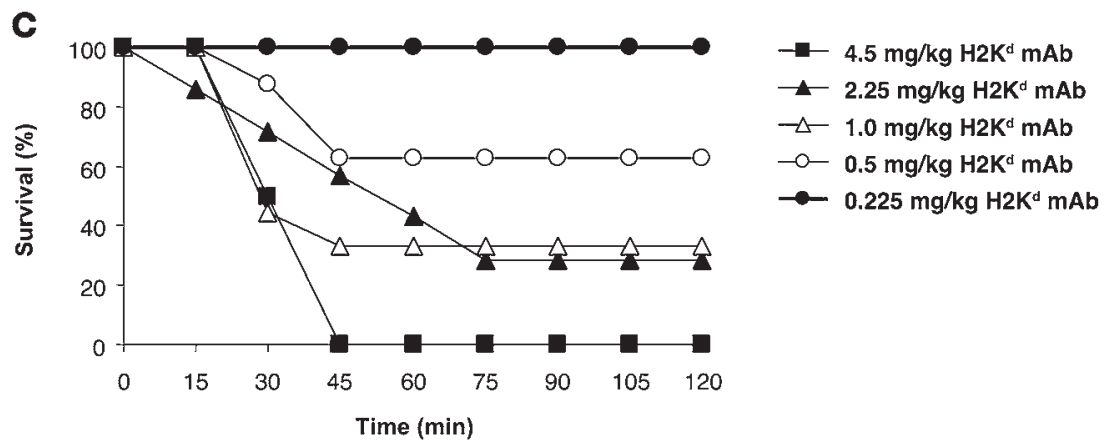

Figure 2

Priming with i.p. LPS restores lung injury after MHC I mAb challenge. (A and B) Extravascular lung water and EVPEs in barrier mice administered i.p. LPS $(0.1 \mathrm{mg} / \mathrm{kg})$ with and without increasing doses of $\mathrm{MHC}$ I mAb. ${ }^{* \star} P<0.05 \mathrm{vs}$. $0 \mathrm{mg} / \mathrm{kg} \mathrm{H} 2 \mathrm{~K}^{\mathrm{d}} \mathrm{mAb} ;{ }^{\dagger} P<0.05 \mathrm{vs}$. $0.5,1.0$, 2.25, and $4.5 \mathrm{mg} / \mathrm{kg} \mathrm{H} 2 \mathrm{~K}^{\mathrm{d}} \mathrm{mAb}$. (C) Survival curves from mice in A and B. $P=0.02$ (Fisher's exact) for trend of increasing mortality, with increasing dose of $\mathrm{MHC}$ I mAb.

striking bronchoalveolar lavage neutrophilia (Supplemental Figure $1, \mathrm{C}$ and D) and both intra-alveolar and interstitial accumulation of Gr-1 $1^{+}$cells (Supplemental Figure 1, E and F).

Priming of the hematopoietic compartment is critical to producing lung injury with 2-event TRALI, with either i.t. or i.p. LPS. To determine the cellular population involved in the priming response, we used bone marrow chimeras to isolate the effects of LPS priming to either stromal cells (e.g., lung endothelium) or the hematopoietic compartment. $\mathrm{H} 2 \mathrm{~K}^{\mathrm{d}}$-expressing mice that are deficient in TLR4 signaling $(\mathrm{C} 3 \mathrm{H} / \mathrm{HeJ}$; TLR4d $)$ were used with WT mice to generate the hematopoietic chimeras. These chimeras were then exposed to LPS and MHC I mAb at approximately 8 weeks after transplant. Irradiation and bone marrow transplant did not significantly affect the lung injury response to i.t. LPS and $\mathrm{mAb}$ in WT mice reconstituted with WT bone marrow (Figure 5, A and B, compare with Figure 1D). When TLR4 ${ }^{\mathrm{d}}$ bone marrow cells were used to reconstitute either TLR4 ${ }^{\mathrm{d}}$ or WT recipients, the lung injury was decreased compared with WT/WT chimeras. Importantly, when
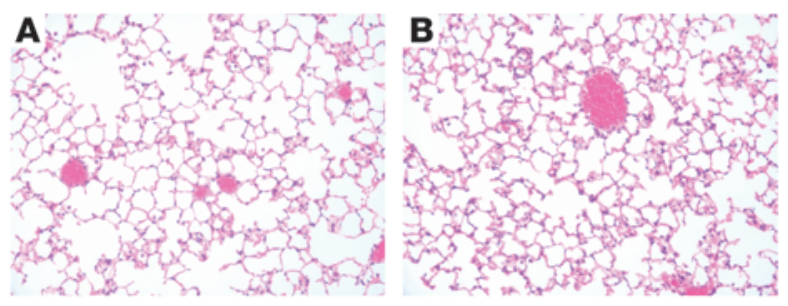

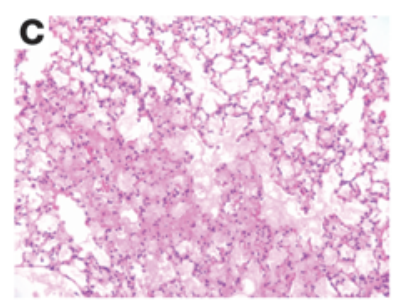

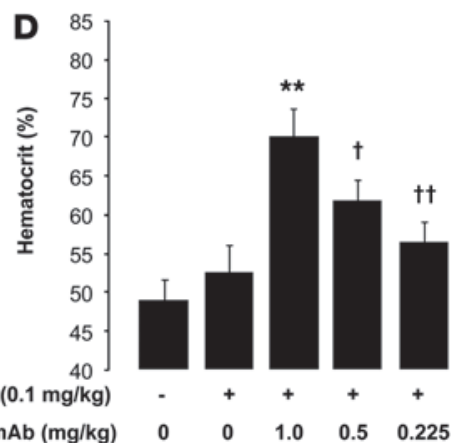

Figure 3

LPS i.p. plus MHC I mAb produces severe ALI with hemoconcentration. (A-C) Representative H\&E-stained lung sections from (A) a control mouse, (B) a mouse given i.p. LPS (24 hours at $0.1 \mathrm{mg} / \mathrm{kg})$, and (C) a mouse given i.p. LPS (0.1 mg/kg) and MHC I mAb (1.0 mg/kg) at $2 \mathrm{hours}$ after injection. Note intra-alveolar edema fluid in C. Original magnification, $\times 200$. (D) Hematocrit response in barrier mice administered i.p. LPS $(0.1 \mathrm{mg} / \mathrm{kg})$ with or without $\mathrm{MHC}$ I mAb. ${ }^{* \star} P<0.05$ vs. all other groups, ${ }^{\dagger} P<0.05$ vs. all other groups, ${ }^{\dagger \dagger} P<0.05$ vs. all other groups. 
A

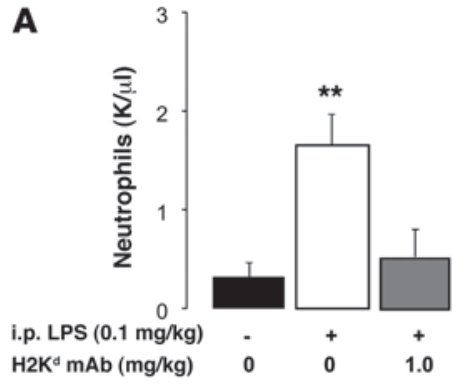

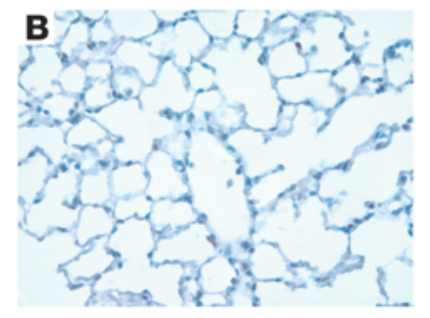
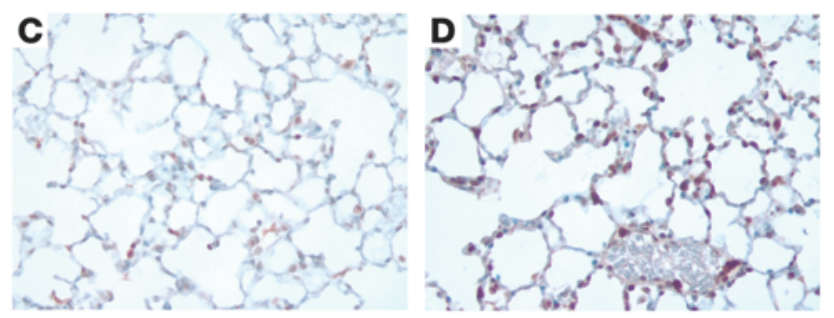

Figure 4

i.p. LPS priming produces peripheral blood neutrophilia, followed by neutropenia and lung neutrophil sequestration, after MHC I mAb challenge. (A) Peripheral neutrophils in control mice and mice administered i.p. LPS $(0.1 \mathrm{mg} / \mathrm{kg})$ with and without MHC I mAb $(1.0 \mathrm{mg} / \mathrm{kg})$. ${ }^{* *} P<0.05 \mathrm{vs}$. other groups. (B-D) Representative Gr-1 mAb immunostaining in (B) control mouse lungs, (C) mice administered i.p. LPS (at 24 hours after injection; $0.1 \mathrm{mg} / \mathrm{kg})$, and (D) mice administered i.p. LPS $(0.1 \mathrm{mg} / \mathrm{kg})$ and MHC I mAb $(1.0 \mathrm{mg} / \mathrm{kg})$ at 2 hours after injection. Original magnification, $\times 400$.

WT bone marrow was used to reconstitute TLR4 ${ }^{\mathrm{d}}$ mice, full lung injury was restored, implying that the hematopoietic cells are the critical compartment required for the priming response. A similar requirement for TLR4 in hematopoietic cells only was observed with i.p. LPS and $\mathrm{mAb}$, which generally produced more severe lung injury (Figure 5, C and D).

Low-dose LPS priming does not increase lung endothelial cell or neutrophil MHC I expression. As a potential mechanism of the priming response induced by LPS, we tested whether isolated lung endothelial cells and/or neutrophils increased expression of MHC I (H2K $)$ after i.p. LPS injection. Lung endothelial cells were isolated by positive magnetic bead selection (21) from BALB/c and TLR4 ${ }^{d}$ mice 24 hours after injection of i.p. LPS $(0.1 \mathrm{mg} / \mathrm{kg})$. $H$-2kd gene expression results on Tie-2 expressing lung endothelial cells normalized to the control gene, L19, are shown in Figure
6A. BALB/c WT lung endothelial cells had decreased $H$ - $2 k d$ gene expression following challenge with low-dose LPS, but $\mathrm{H} 2 \mathrm{~K}^{\mathrm{d}}$ expression was increased following high-dose LPS $(10 \mathrm{mg} / \mathrm{kg})$. TLR4 ${ }^{d}$ mice had higher baseline $\mathrm{H} 2 \mathrm{~K}^{\mathrm{d}}$ expression that did not significantly change following low-dose LPS injection. In peripheral blood from these mice, neutrophil surface expression of $\mathrm{H} 2 \mathrm{~K}^{\mathrm{d}}$ did not significantly change with low-dose LPS challenge in either BALB/c or TLR4 ${ }^{\mathrm{d}}$ animals (Figure $6 \mathrm{~B}$ ).

Two-event TRALI produces mild thrombocytopenia and sequestration of platelets in the lungs. Thrombocytopenia has been occasionally reported in clinical TRALI (22-24), and we observed mild thrombocytopenia in mice primed with i.p. LPS (Figure 7A), which worsened after MHC I mAb administration. We explored the sequestration of platelets in the lungs of TRALI using a platelet specific marker, CD41 (GPIIb). Platelet staining was observed in both normal mouse

\section{Figure 5}

WT and TLR4-deficient (TLR4 ${ }^{\mathrm{d}}$ ) bone marrow chimeras reveal that WT TLR4 on hematopoietic cells is critical to the priming phenotype. (A and B) Extravascular lung water and EVPEs in WT and TLR4d bone marrow chimeras administered i.t. LPS $(0.1 \mathrm{mg} / \mathrm{kg})$ and $\mathrm{MHC}$ I $\mathrm{mAb}(4.5 \mathrm{mg} / \mathrm{kg}) .{ }^{*} P<0.05 \mathrm{vs}$. WT/WT and TLR4 deficient/WT (recipient/bone marrow donor). (C and D) Extravascular lung water and EVPEs in WT and TLR4deficient bone marrow chimeras administered i.p. LPS $(0.1 \mathrm{mg} / \mathrm{kg})$ and $\mathrm{MHC}$ I $\mathrm{mAb}(1.0 \mathrm{mg} / \mathrm{kg})$. ${ }^{*} P<0.05 \mathrm{vs}$. WT $/$ WT and TLR4 deficient/WT (recipient/bone marrow donor).
A

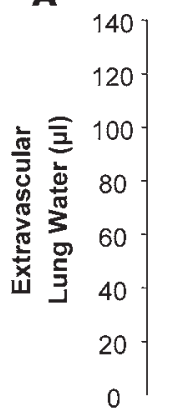

Recipient

BM Donor

C

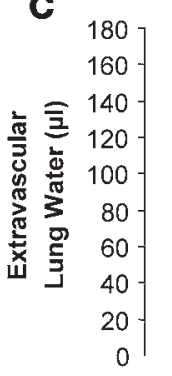

Recipient

BM Donor
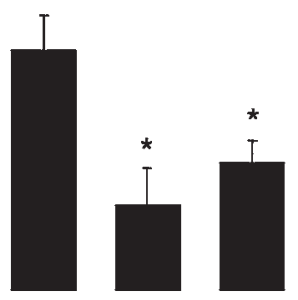

WT

TLR4 $^{d}$

WT

TLR4

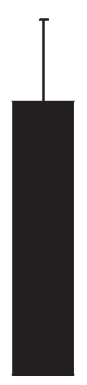

TLR4 $^{\mathrm{d}}$

WT

TLR4

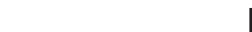

D

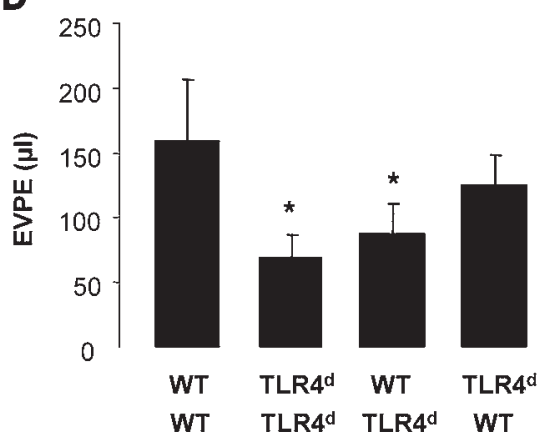


A

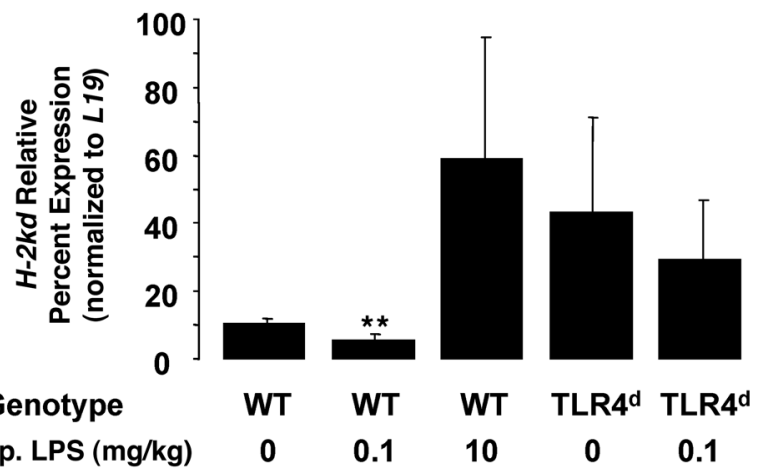

B

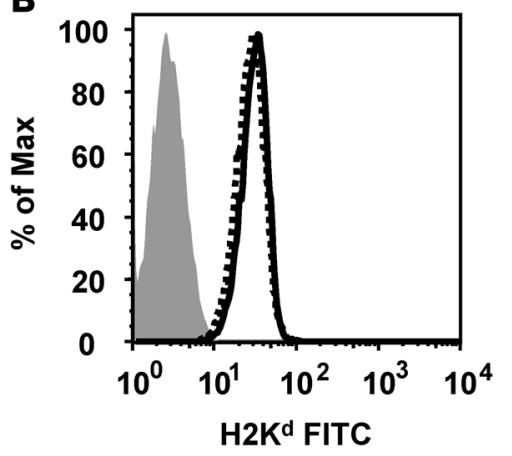

$\square$ TLR4 $^{\text {d }}$ \& no LPS, isotype control - TLR4 ${ }^{\mathrm{d}}$ \& no LPS .. TLR4 ${ }^{\mathrm{d}}+$ LPS $(0.1 \mathrm{mg} / \mathrm{kg})$

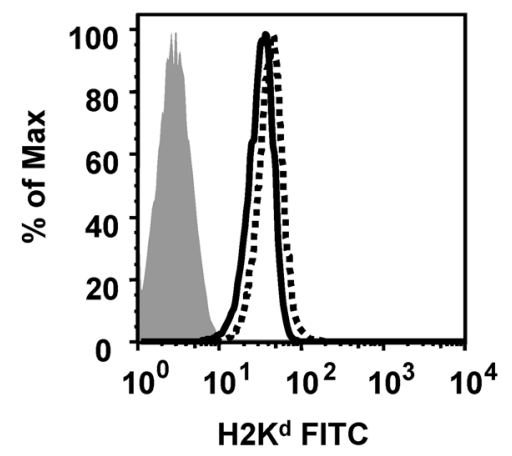

\section{WT \& no LPS, isotype control - WT \& no LPS -.. WT + LPS $(0.1 \mathrm{mg} / \mathrm{kg})$}

Figure 6

Low-dose LPS priming does not increase lung endothelial or neutrophil MHC I expression. (A) Relative gene expression results for $H-2 k d$ normalized to the control gene, $L 19$, in Tie-2expressing lung endothelial cells isolated from WT and TLR4 ${ }^{d}$ mice administered i.p. LPS $\left(0,0.1,10 \mathrm{mg} / \mathrm{kg} ; 24\right.$ hours prior to cell isolation). ${ }^{\star \star} P<0.05$ vs. all other groups. (B) $\mathrm{H} 2 \mathrm{~K}^{\mathrm{d}}$ fluorescence intensity in Ly- $6 \mathrm{G}^{+} / \mathrm{CD} 11 \mathrm{~b}^{+}$peripheral blood cells from WT and TLR4 ${ }^{\mathrm{d}}$ mice administered no LPS or LPS ( $0.1 \mathrm{mg} / \mathrm{kg} ; 24$ hours prior to cell isolation).

lungs and in lungs primed with i.p. LPS $(0.1 \mathrm{mg} / \mathrm{kg})$. However, there was a sharp increase in platelet staining in mice with TRALI (LPS and MHC I mAb-injected mice) (Figure 7, B-D).

Neutrophil depletion protects mice from ALI and lung platelet sequestration. We have previously shown that depletion of circulating neutrophils protects mice from MHC I mAb-induced lung injury (5). In these 2-event experiments with LPS priming, depletion of neutrophils with Gr-1 mAb (>95\% depletion; data not shown) also significantly protects mice from TRALI (Figure 8A). Using ${ }^{51} \mathrm{Cr}$ labeled platelets, 2 -event TRALI produced an increase in lung platelet counts, which was reversed in mice with prior depletion of neutrophils, implying that neutrophils were critical for the sequestration of platelets (Figure 8B). In contrast, using a whole lung myeloperoxidase (MPO) assay, neutrophils were sequestered after i.t. LPS with or without $\mathrm{mAb}$, but prior platelet depletion using immune serum failed to abrogate this effect (Figure 8C).

Platelet depletion protects mice from 2-event TRALI and improves survival. Administration of a rabbit, anti-mouse platelet serum (25 $\mu$ l, i.p.) versus control serum produced an approximately $90 \%$ decrease in the circulating platelet counts at 2 hours (Figure 9A) that was sustained for at least 24 hours. Platelet depletion prior to LPS priming (i.t. or i.p.) and anti-MHC I mAb challenge signifi- cantly protected the animals from ALI (Figure 9, B and C). In the i.p. LPS-primed mice challenged with MHC I mAb, only $20 \%$ of the animals survived to 2 hours, compared with $100 \%$ of the platelet-depleted animals (Figure 9D). There were no bleeding complications in the platelet-depleted animals.

Platelet depletion protects mice from acid-induced but not byperoxia-induced $A L I$. It has been reported in a mouse model of acid instillation plus mechanical ventilation that platelet depletion using busulfan or antiplatelet serum significantly protects mice from ALI (20). We used our previously reported model of noninvasive i.t. acid instillation (25) to determine its dependency on platelets (Supplemental Figure 2). Administration of a one-third normal saline solution, $\mathrm{pH}$ 1.5, i.t. produced minimal ALI. When the $\mathrm{pH}$ was decreased to 1.0, moderate-to-severe ALI was produced at 4 hours. When mice were platelet-depleted using immune serum prior to acid instillation, there was significant protection from ALI (Supplemental Figure 2, $A$ and B). As an additional control, we used $c-m l^{-/-}$mice, which lack the thrombopoietin receptor and are constitutively thrombocytopenic (mean platelet count of $\sim 100 \mathrm{~K} / \mu \mathrm{l}$; data not shown) (26). These mice were also significantly protected from acid-induced ALI (Supplemental Figure 2, A and B).

Our acid ALI model is also neutrophil dependent, as shown by the Gr-1 mAb depletion studies in Supplemental Figure 2C. As an additional experimental control to test platelet dependency in ALI, we used a neutrophil-independent model of ALI, acute hyperoxia (27). We have previously reported that continuous exposure to more than $95 \% \mathrm{O}_{2}$ produces an $\mathrm{LD}_{50}$ at approximately 96 hours in WT mice (28). There was a mortality disadvantage in $c-m \mathrm{pl}^{l^{-/}}$mice at 96 hours of hyperoxia compared with WT controls (Supplemental Figure 2D).

Targeting the P selectin and CD11b/CD18 pathways fails to protect mice from TRALI. Adhesive interactions, which have been well described, between platelets and neutrophils are mediated via platelet $P$ selectin binding by neutrophil P selectin glycoprotein ligand-1 (PSGL-1) $(29,30)$ and binding of platelet glycoprotein Ib $\alpha$ (GPIb $\alpha)$ by the multifunctional leukocyte integrin, MAC-1 (CD11b/CD18) (31). The $\mathrm{P}$ selectin pathway has been reported to be critical in acidinduced ALI (20), and blocking GPIb $\alpha$ and MAC-1 interactions is protective in acute systemic vascular injury (32) and prevents neutrophil-derived microparticle-induced platelet activation (33).

In our model of acid ALI, we observed modest protection in mice pretreated with $\mathrm{P}$ selectin-blocking $\mathrm{mAb}$ (Figure 10A). However, we failed to detect differences in the lung injury response in Psgl1 ${ }^{-/}$mice compared with WT mice (Figure 10A). Additionally, in the 2-hit TRALI model, $\mathrm{P}$ selectin-blocking $\mathrm{Ab}$ given prior to LPS priming and prior to MHC I $\mathrm{mAb}$ challenge failed to ameliorate lung injury (Figure 10A) or platelet sequestration in the lungs (Supplemental Figure 3, A and B). 
A

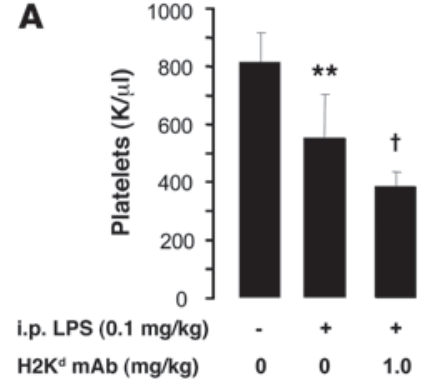

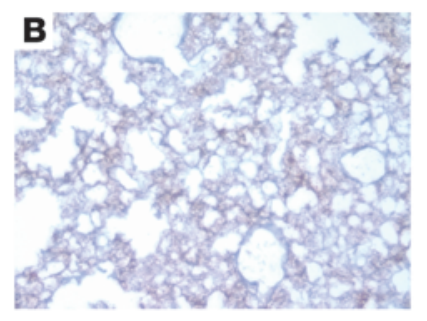
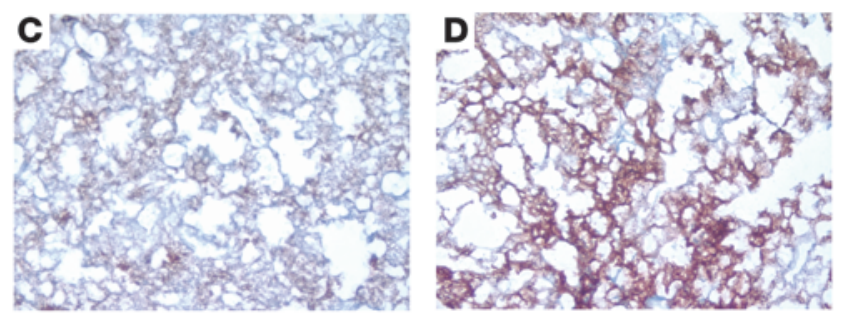

Figure 7

Two-hit TRALI with LPS priming leads to mild thrombocytopenia and sequestration of platelets in the lung microcirculation. (A) Peripheral blood platelet counts in control mice and mice administered i.p. LPS $(0.1 \mathrm{mg} / \mathrm{kg})$ with and without $\mathrm{MHC} \mathrm{I} \mathrm{mAb}(1.0 \mathrm{mg} / \mathrm{kg}) .{ }^{* *} P<0.05 \mathrm{vs}$. other groups, ${ }^{\dagger} P<0.05$ vs. other groups. (B-D) Representative CD41 immunostaining in (B) control mouse lungs, (C) mice administered i.p. LPS (at 24 hours after injection; $0.1 \mathrm{mg} / \mathrm{kg})$, and (D) mice administered i.p. LPS $(0.1 \mathrm{mg} / \mathrm{kg})$ and $\mathrm{MHC} I \mathrm{mAb}(1.0 \mathrm{mg} / \mathrm{kg})$ at 2 hours after injection. Original magnification, $\times 200$.

Using flow cytometry on peripheral blood, we detected an increase in mean fluorescence for CD $11 \mathrm{~b}$ in $\mathrm{Ly}-6 \mathrm{G}^{+}$cells exposed to i.p. LPS and MHC I mAb compared with cells exposed to LPS alone (Figure 10B). Despite the upregulation of CD11b in 2-event TRALI, when we used CD18-deficient mice $\left(\mathrm{H} 2 \mathrm{~K}^{\mathrm{d}+}\right)$, there was no protection from lung injury (Figure 10C) or lung platelet sequestration (Supplemental Figure 3, C and D) compared with that in WT controls. Additionally, neither a CD11b-blocking Ab nor an Ab blocking the GPIb $\alpha$-binding site on MAC-1 were able to decrease lung injury in the 2-event TRALI model (Figure 10C). To explore the potential role of fibrinogen-mediated platelet binding to MAC-1 (34), we used Ancrod (2.5 units) to deplete plasma fibrinogen levels (>97\% depletion; data not shown). However, fibrinogen depletion did not decrease lung injury in our model (Figure 10D).

Treatment with aspirin protects mice in 2-event TRALI. We treated mice with the cyclooxygenase inhibitor, acetylsalicylic acid (ASA; aspirin), or vehicle (DMSO) immediately prior to i.p. LPS priming and 2 hours prior to challenge with MHC I mAb or control (PBS). We chose a dose of aspirin that has previously been used in mouse studies of acid-induced ALI (35). Aspirin treatment had no effect on lung neutrophil sequestration in response to MHC I mAb (Supplemental Figure 3E); however, it largely prevented the development of lung injury and prevented mortality (Figure 11, A-C), decreased plasma thromboxane $B_{2}$ levels (Figure 11D), and decreased platelet sequestration in the lungs (Supplemental Figure 3, F and G) compared with controls administered vehicle (DMSO).

\section{Discussion}

The major conclusions from this study are that (a) an immune priming event is necessary to produce maximal injury in our TRALI model; (b) TLR4 signaling on hematopoietic cells is required for priming; (c) there is neutrophil-dependent platelet sequestration in 2-event TRALI; and (d) TRALI depends on participation by both platelets and neutrophils, with the depletion of platelets or antiplatelet therapy preventing TRALI.

We initially developed the first mouse model of TRALI in order to better understand the pathogenesis of this serious complication of transfusion therapy. TRALI is the leading cause of transfusion-related mortality reported in the UK and US, yet it is generally agreed that it is under-recognized and underreported. Among the major gaps in our understanding of TRALI are the specific factors that predispose a patient to developing lung injury. For example, we have learned from "look-back" investigations that trace the recipients of blood products from an implicated TRALI donor that TRALI occurs in the minority of patients predicted to have an antigen match to transfused HLA or neutrophil $\mathrm{Ab}(3,11)$.

We were surprised by the results in our TRALI mouse model when we switched from animals housed in nonbarrier rooms to animals housed in barrier, specific pathogen-free environments. When these barrier mice (obtained from the same vendor) were challenged with the identical MHC I mAb (same Ab batch), there was dramatic protection from ALI. Interestingly, the barrier mice had significantly lower circulating neutrophils than the nonbarrier animals, which could reflect a more "primed" immune system for mice housed in the less sterile environmental conditions. When the barrier mice were challenged with MHC I mAb, while producing minimal ALI, there was significant hemoconcentration - a surrogate for plasma leakage. The extravascular plasma leakage, however, did not develop in the lungs of these animals and suggests that injury in other tissues was occurring in the nonprimed/barrier mice.

We were able to restore lung injury in the barrier mice by exposing them to low-dose LPS, by either i.t. or i.p. injection. The LPS alone did not produce lung injury. However, when LPS was combined with MHC I mAb, severe lung injury was produced, especially with the i.p. route of administration. In fact, i.p. LPS priming produced similar mortality at 2 hours compared with our previous publication (5), but with approximately one-tenth the dose of mAb (0.5 vs. $4.5 \mathrm{mg} / \mathrm{kg})$. Significant hemoconcentration was observed in the 2-event model with i.p. LPS priming, similar to that of the barrier mice challenged with MHC I mAb alone, but the plasma leakage was now concentrated to the lungs, which also is the principal target organ in clinical TRALI. The increased severity of Ab-induced lung injury with the i.p. versus the i.t. routes of LPS administration may be explained by the recruitment patterns of the neutrophils to the lung. The i.t. LPS priming produces prominent intra-alveolar neutrophil recruitment, which may be less effective in responding to the i.v. MHC I mAb than the prominent intravascular neutrophil recruitment with i.p. LPS.

Low-dose LPS priming produced peripheral blood neutrophilia and lung sequestration of neutrophils, as shown by both MPO content and Gr-1 mAb immunohistochemistry. Similar to what has been reported in clinical TRALI (36) and coincident with lung deposition of neutrophils, the mice developed peripheral blood neutropenia following $\mathrm{MHC}$ I mAb challenge. We used mice deficient in TLR4 signaling (C3H/HeJ on BALB/c background) and generated bone marrow chimeras to help determine the cell type 
A

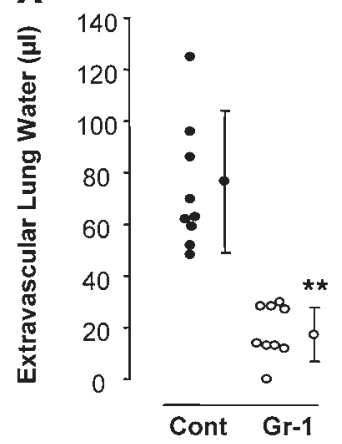

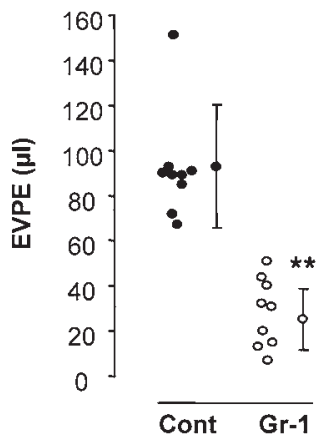

B

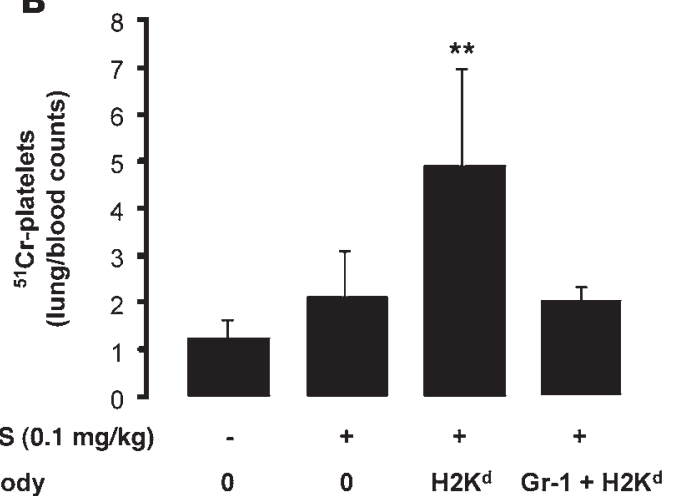

$H 2 K^{d} \quad G r-1+H 2 K^{d}$

C

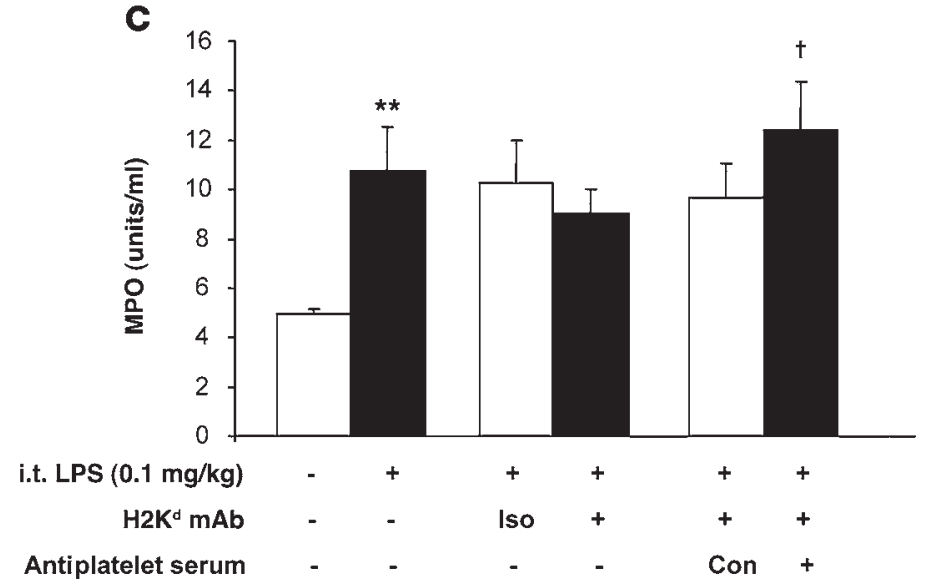

\section{Figure 8}

Neutrophil depletion protects mice from 2-event TRALI and from platelet sequestration in the lungs. Platelet depletion does not affect lung neutrophil sequestration. (A) Extravascular lung water and EVPEs in BALB/c WT mice pretreated with either Gr-1 mAb (250 $\mu \mathrm{g}$, i.p.) or isotype control (cont) and administered i.t. LPS $(0.1 \mathrm{mg} / \mathrm{kg})$, followed by MHC I mAb $(4.5 \mathrm{mg} / \mathrm{kg})$. Vertical lines indicate mean $\pm \mathrm{SD}$. ${ }^{\star \star} P<0.05 \mathrm{vs}$. isotype control. (B) ${ }^{51} \mathrm{Cr}$-platelet counts (whole lung/100 $\mu \mathrm{l}$ blood) in WT control mice and mice given i.t. LPS $(0.1 \mathrm{mg} / \mathrm{kg})$ with or without MHC I mAb. The far right bar represents mice pretreated with Gr-1 mAb. ${ }^{*} P<0.05$ vs. all other groups. (C) Whole lung MPO (units/ml lung supernatant) measurements. LPS (0.1 mg/kg, i.t.), MHC I mAb (4.5 mg/kg), antiplatelet serum (25 $\mu$ l, i.p.) were used. Iso, isotype control mAb; Con, control rabbit serum; NS, normal saline. ${ }^{* *} P<0.05$ vs. normal saline; ${ }^{\dagger} P<0.05$ vs. control serum.

involved in the LPS priming. Using i.t. and i.p. routes of administration, the priming response required WT TLR4 on hematopoietic cells. This result has important implications, since TLR4 is present on both immune cells and tissue stromal cells, such as lung endothelium and epithelium. TLR4 on endothelial cells has previously been shown to be essential to neutrophil migration into the lung after i.p. LPS (37).

The mechanism of the LPS priming response in our model does not appear to be related to increased cognate antigen expression $\left(\mathrm{H} 2 \mathrm{~K}^{\mathrm{d}}\right)$ on the lung endothelium or on circulating neutrophils. We have previously shown that MHC I-null neutrophils are sufficient to produce lung injury after MHC I mAb (5). Along with neutrophils, platelets are a key hematopoietic cell in our model and are known to express TLR4 (38). The increase in plasma thromboxane $\mathrm{B}_{2}$ levels observed in our TRALI model provides evidence for cyclooxygenase activation that may contribute to lung injury. Notably, plasma thromboxane $\mathrm{B}_{2}$ levels were significantly higher in WT versus TLR4-deficient animals after low-dose LPS and MHC I mAb. Taken together, we hypothesize that unprimed platelets in the TLR4-deficient mice produce less cyclooxygenase activation in response to MHC I mAb, which is associated with less ALI.
Peripheral blood thrombocytopenia and lung platelet sequestration were associated with the dynamic neutrophil changes, as determined by both platelet (CD41) immunohistochemistry and platelet radiolabeling $\left({ }^{51} \mathrm{Cr}\right)$ experiments. Thrombocytopenia has been reported in several cases of clinical TRALI, though always associated with leukopenic reactions. Platelet sequestration has also been reported in patients with ARDS by radiolabeling techniques (39) and experimentally with systemic LPS administration (38). The sequestration of platelets after MHC I mAb challenge was critically dependent on the presence of neutrophils, but platelet depletion did not affect lung neutrophil accumulation. This finding suggests that sequestered neutrophils in the lung are capturing platelets after MHC I mAb challenge and is similar to the pattern that has been reported after i.p. LPS administration alone (38).

Importantly, neutrophil depletion, platelet depletion, or treatment with aspirin substantially protected mice from 2 -event TRALI. The platelet depletion and aspirin treatment studies resulted in a striking mortality advantage at 2 hours after Ab challenge. In another neutrophil-dependent model of ALI, i.t. acid, using platelet depletion or $c-m \mathrm{pl}^{-/-}$mice that are constitutively thrombocytopenic, there was also marked protection from ALI. However, 
A
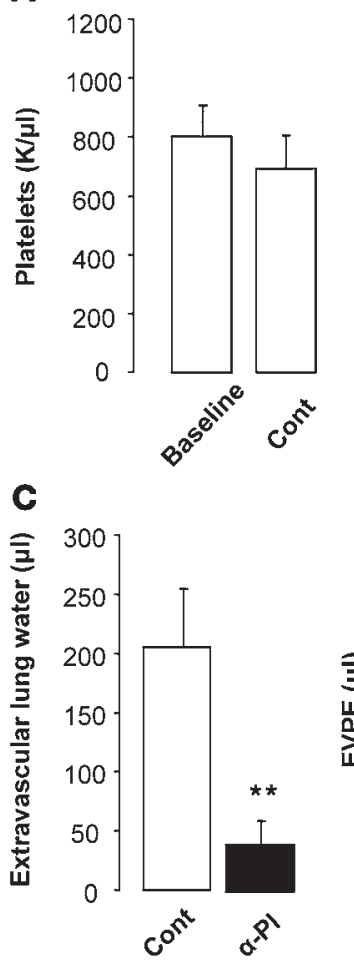
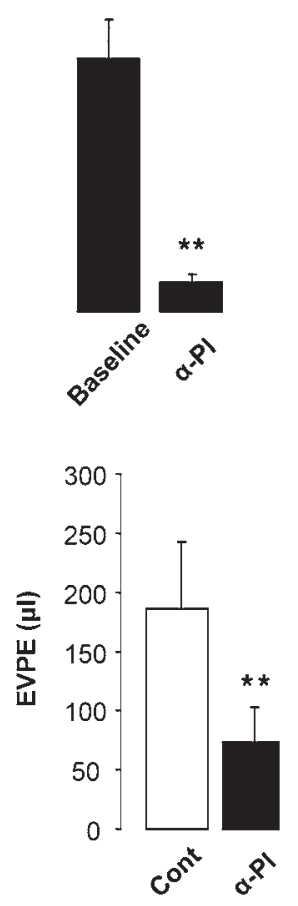
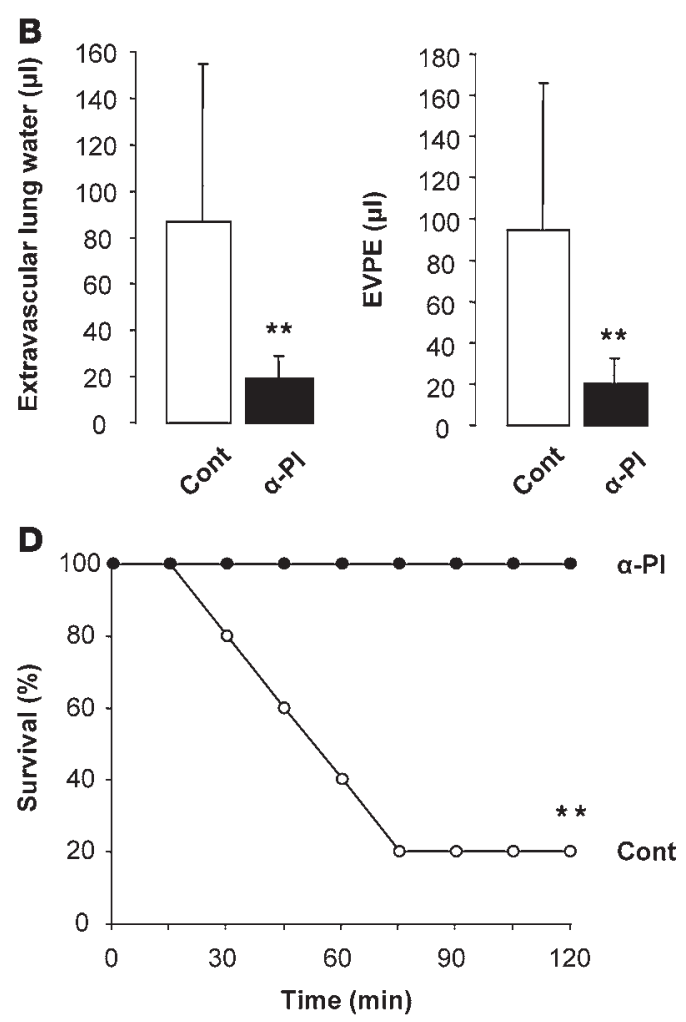

Figure 9

Platelet depletion protects mice from 2-hit TRALI. (A) Peripheral blood platelet counts in BALB/c WT mice at baseline and after receiving either control or antiplatelet $(\alpha-\mathrm{PI})$ serum. ${ }^{* \star} P<0.05 \mathrm{vs}$. baseline. (B) Extravascular lung water and EVPEs in mice challenged with i.t. LPS $(0.1 \mathrm{mg} / \mathrm{kg})$ and $\mathrm{MHC}$ I mAb $(4.5 \mathrm{mg} / \mathrm{kg})$ and pretreated with either control or antiplatelet serum. ${ }^{* \star} P<0.05$ vs. control. (C) Extravascular lung water and EVPEs in mice challenged with i.p. LPS $(0.1 \mathrm{mg} / \mathrm{kg})$ and $\mathrm{MHC}$ I mAb $(1.0 \mathrm{mg} / \mathrm{kg})$ and pretreated with either control or antiplatelet serum. ${ }^{\star \star} P<0.05$ vs. control. (D) Survival curves from mice in $\mathbf{C}$. ${ }^{\star \star} P<0.05$ vs. antiplatelet serum.

there was no protection in $c-m \mathrm{pl}^{-/-}$mice challenged with hyperoxia, a model that is neutrophil independent. In summary, using direct (acid) and indirect (TRALI) neutrophil-dependent models of ALI, platelets are essential for the development ALI.

We explored potential molecular interactions between neutrophils and platelets, using knockout animals and blocking $\mathrm{Ab}$ strategies. While P selectin blockade modestly protected from acid ALI as has been reported (20), using mice deficient in PSGL-1, a major neutrophil ligand for $\mathrm{P}$ selectin, no protection was observed. In addition, no protection was observed in the TRALI model with $\mathrm{P}$ selectin blockade.

MAC-1 (CD11b/CD18) is a multifunctional leukocyte integrin that is upregulated with leukocyte priming and activation and can lead to endothelial adhesion and also direct interaction with platelets through platelet GPIb $\alpha$ (32) and fibrinogen-bound GPIIbIIIa (34). It was therefore an attractive target to potentially explain neutrophil-platelet interactions in our model. Although we observed an upregulation of surface CD11b on neutrophils after MHC I mAb challenge, targeting MAC-1 with blocking Ab strategies, knockout animals, or fibrinogen depletion yielded no protection from ALI.

Since our experiments did not identify a specific molecular pathway between neutrophils and platelets that could explain TRALI, there are 2 possible interpretations. First, there may be molecular or structural interactions between platelets and neutrophils that have not been identified that could be important in experimental TRALI. Second, neutrophil-mediated platelet capture in the lungs may be occurring in the absence of direct ligand-receptor interactions. Neutrophils recruited to the lungs by LPS priming and Fc $\gamma$ receptor engagement of endothelial-bound MHC I Ab may produce endothelial damage that allows platelet capture to occur. The sequestered platelets can release mediators (e.g., thromboxane $\mathrm{A}_{2}$ ) that can activate neutrophils and amplify tissue injury; this can be blocked with a platelet inhibitor such as aspirin. The results of our platelet depletion and aspirin experiments support this hypothesis, since neutrophil sequestration in the lungs was unaffected by these interventions, but the neutrophils produced no lung injury.

We believe our results have several important implications in the study of TRALI and ALI in general. First, the importance of immune priming in experimental TRALI may help explain the unique susceptibility of a minority of patients transfused with a HLA or neutrophil Ab that matches recipient antigen. Our 2-event model has the substantial advantage of adding clinical relevance to the study of TRALI, since most patients who develop TRALI or ALI are not the human correlate of healthy, young experimental animals, housed in sterile environments, with low circulating neutrophils and with no associated comorbidities. Second, the role of platelets in the pathogenesis of TRALI has previously been isolated to biological mediators, such as HLA or neutrophil Ab, lysophosphatidylcholines (15), or soluble CD40 
A

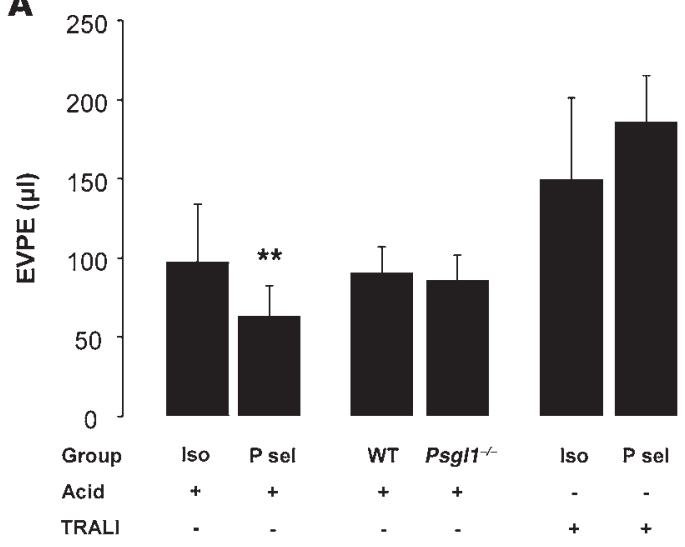

C

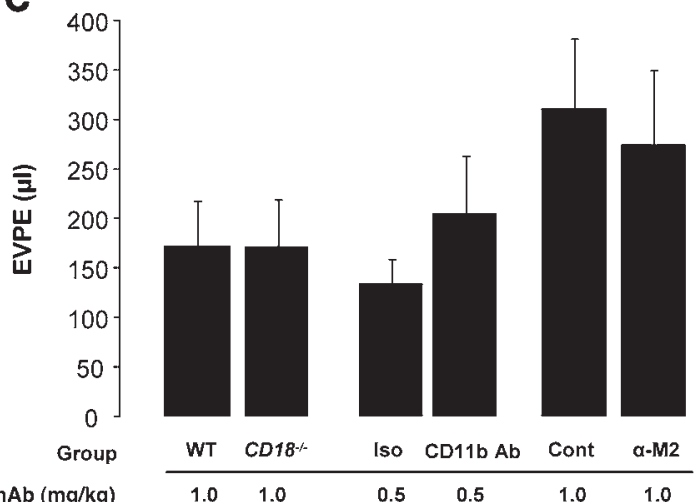

B

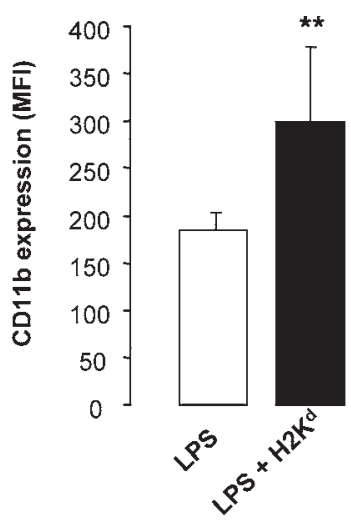

D

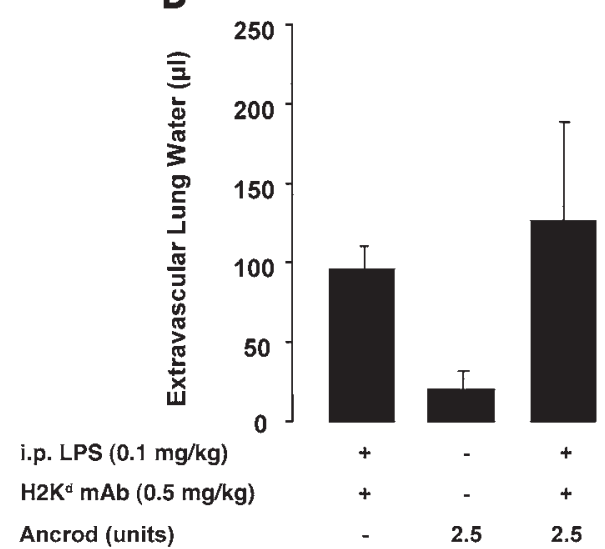

Figure 10

Blocking P selectin or MAC-1 fails to protect mice from 2-hit TRALI. (A) Lung vascular permeability (EVPE) in acid (pH 1.0) and 2-event TRALI (i.p. LPS $[0.1 \mathrm{mg} / \mathrm{kg}]$ plus MHC I mAb $[1.0 \mathrm{mg} / \mathrm{kg}])$ in WT mice pretreated with $\mathrm{P}$ selectin (P sel) $(30 \mu \mathrm{g})$ or isotype control $\mathrm{mAbs}$. ${ }^{* \star} P<0.05 \mathrm{vs}$. isotype control (acid). Additionally, WT and $P s g / 1^{-1-}$ mice were challenged with i.t. acid. Measurement of extravascular lung water revealed a similar pattern among the groups (data not shown). (B) Flow cytometry staining for CD11b expression (MFI) in Ly-6G+ cells from control mice, i.p. LPS $(0.1 \mathrm{mg} / \mathrm{kg})$ and LPS plus MHC I mAb $(1.0 \mathrm{mg} / \mathrm{kg}) .{ }^{* \star} P<0.05 \mathrm{vs}$. other groups. (C) Lung vascular permeability (EVPE) in $2-e v e n t$ TRALI (i.p. LPS [0.1 mg/kg] plus MHC I mAb [0.5-1.0 mg/kg]) in WT and Cd18 and control Abs. (D) Extravascular lung water in WT mice administered Ancrod ( 2.5 units i.p., 24 hours and 2 hours prior to H2K $\left.\mathrm{K}^{\mathrm{d}} \mathrm{Ab}\right)$ to deplete fibrinogen and then challenged with LPS plus MHC I mAb.

ligand (40), which are present in the plasma fraction of the platelet units. We have now shown that platelets are a critical effector cell that along with neutrophils are necessary to produce TRALI. It is possible that the higher incidence of TRALI from platelet transfusions compared with other cellular blood products (10) is a result of both the soluble biological mediators and the platelets themselves. Finally, it is possible that patients with thrombocytopenia or neutropenia (or both) are protected from TRALI. Although ALI can develop in neutropenic hosts, the reported causes of ALI in these patients are secondary to bacterial infections, which could produce direct lung injury $(41,42)$. Epidemiologic investigations are needed to determine the susceptibility to TRALI in unique populations, such as neutropenic, thrombocytopenic patients after bone marrow transplant and patients receiving antiplatelet therapies.

In conclusion, experimental TRALI is critically dependent on immune priming of circulating hematopoietic cells prior to $\mathrm{Ab}$ challenge. Depletion of neutrophils abolishes lung injury and also the sequestration of platelets in the lungs. Depletion of platelets and platelet inhibition with aspirin markedly protects animals from lung injury. There is no effective pharmacotherapy for ALI, a syndrome that afflicts close to 200,000 people each year in the US, with a mortality approaching $40 \%$ (43). Targeting platelets may be a promising area for pharmacologic development.

\section{Methods}

Experimental animals. BALB/c WT mice $\left(\mathrm{H} 2 \mathrm{~K}^{\mathrm{d}}\right)$ were purchased from Charles River Laboratories; TLR4 ${ }^{\mathrm{d}}\left(\mathrm{C} 3 \mathrm{H} / \mathrm{HeJ}, \mathrm{H} 2 \mathrm{~K}^{\mathrm{d}+}\right)$, C57BL/ $6 \mathrm{WT}$, and Psgl1-/ mice (C57BL/6 background) were purchased from The Jackson Laboratory; c-mpl-- mice (C57BL/6 background) were obtained from a Material Transfer Agreement from Genentech; and $\mathrm{CD} 18^{-/}$mice $\left(\mathrm{H}_{2} \mathrm{~K}^{\mathrm{d}}+\right)$ were supplied by Eric Brown and Clifford Lowell (UCSF). All experimental procedures were performed in 8- to 12-week-old male mice and were approved by the UCSF Committee on Animal Research. For all experimental procedures, 4-10 mice were used in each group.

$A b s$ and reagents. The $\mathrm{MHC} I \mathrm{mAb}\left(\mathrm{H}_{2} \mathrm{~K}^{\mathrm{d}} ; \operatorname{IgG}_{2 \mathrm{a}}, \mathrm{K}\right)$ was produced from a hybridoma (34-1-2S; ATCC) and purified using standard techniques. Gr-1 (clone RB6-8C5), Ly-6G (clone 1A8), P selectin (clone RB40.34), CD11b (clone M1/70), CD41 (clone MWReg30), and matched isotype control mAbs were purchased from BD Biosciences. Rabbit, anti-mouse platelet 
A

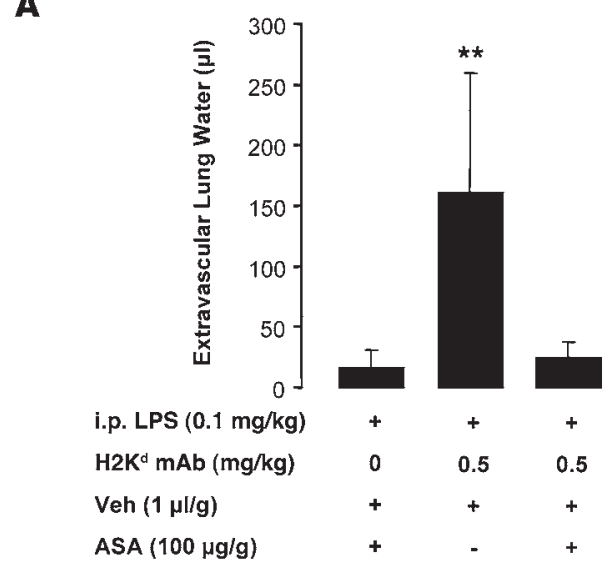

C

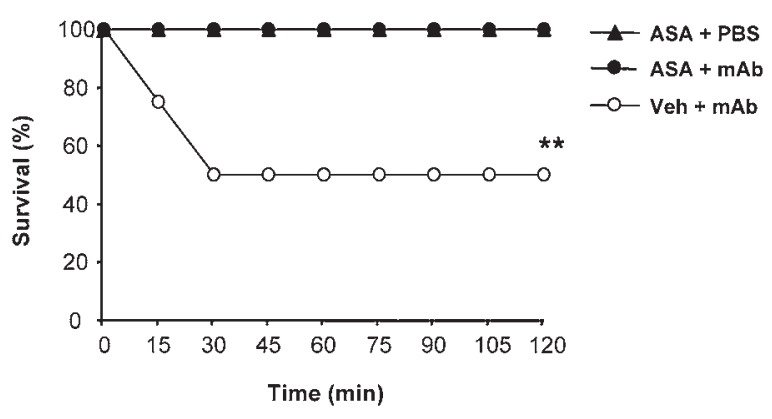

B

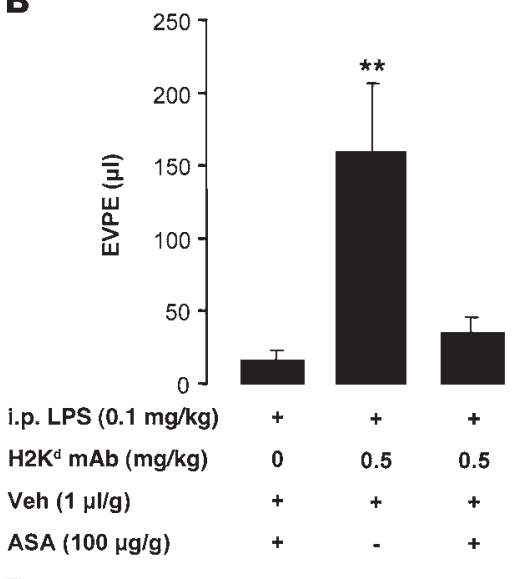

D

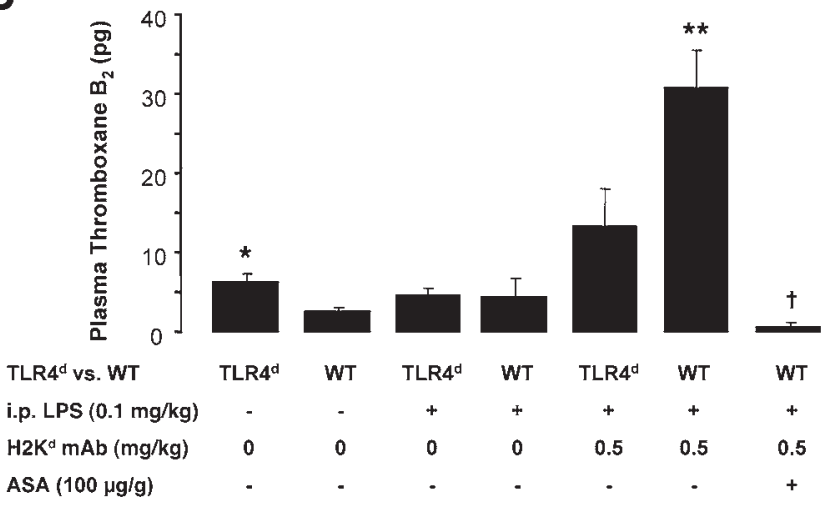

Figure 11

Treatment with aspirin prevents TRALI. (A-C) Extravascular lung water (A), lung vascular permeability (EVPE) (B), and survival curves (C) in mice treated with aspirin (ASA; $100 \mu \mathrm{g} / \mathrm{g}$, i.p.) or vehicle (veh) (DMSO; $1 \mu \mathrm{l} / \mathrm{g}$, i.p.) 30 minutes prior to LPS (0.1 mg/kg, i.p.) and again 2 hours prior to $\mathrm{MHC}$ I mAb $(0.5 \mathrm{mg} / \mathrm{kg})$ or control (PBS). Data were obtained 2 hours after injection of MHC I mAb or PBS. ${ }^{* \star} P<0.05 \mathrm{vs}$. other groups. (D) Plasma thromboxane $B_{2}$ levels in TLR4d and WT mice challenged with LPS $(0.1 \mathrm{mg} / \mathrm{kg}$, i.p.), MHC I mAb $(0.5 \mathrm{mg} / \mathrm{kg})$, and ASA (100 $\mu \mathrm{g} / \mathrm{g})$. ${ }^{\star} P<0.05$ vs. WT plus no LPS; ${ }^{* *} P<0.05$ vs. all other groups, ${ }^{\dagger} P<0.05$ vs. all other groups.

serum and control rabbit serum were purchased from Accurate Chemical. The anti-M2 Ab (rabbit, anti-mouse) was a gift of D. Simon (Cleveland Clinic, Cleveland, Ohio, USA). LPS from Escherichia coli O55:B5 (SigmaAldrich) was used in the i.t. and i.p. priming experiments. For the fibrinogen depletion studies, Ancrod (Neurobiological Technologies) was administered i.p. (2.5 units/mouse) 24 hours and again 2 hours prior to MHC I $\mathrm{mAb}$ challenge. Plasma fibrinogen levels were measured with a mouse fibrinogen ELISA (GenWay). Thromboxane $\mathrm{B}_{2}$ plasma levels were determined by ELISA (Amersham).

Two-event TRALI model. Animals were anesthetized with i.p. ketamine $(80 \mathrm{mg} / \mathrm{kg})$ and xylazine $(12 \mathrm{mg} / \mathrm{kg})$ for either i.t. instillations or jugular vein injections. Isoflurane anesthesia was used to anesthetize mice for i.p. injections. For i.t. instillations, mice were suspended by their incisors at a 45-degree angle, and the method of direct visual instillation was used to noninvasively deliver the LPS (44). Mice were primed with either i.t. or i.p. LPS $(0.1 \mathrm{mg} / \mathrm{kg}) 24$ hours prior to challenge with MHC I mAb $(0.225-4.5 \mathrm{mg} / \mathrm{kg})$ or isotype control $\mathrm{mAb}$ injected into the jugular vein. For jugular vein injections, mice were placed supine on a warming blanket, and the jugular vein was punctured with a 30-gauge sterile needle attached to PE-10 tubing. In some experiments, an aliquot of blood $(200 \mu \mathrm{l})$ was removed for baseline measurements prior to injecting the biological agent. Mice were euthanized with i.p. pentobarbital $(200 \mathrm{mg} / \mathrm{kg})$ when they appeared moribund or at 2 hours after MHC I mAb injection.
Acid ALI model. We used our method of noninvasive instillation to deliver acid (one-third normal saline; $\mathrm{pH} 1.0-1.5 ; 3 \mu \mathrm{l} / \mathrm{g}$ ) directly into the trachea of anesthetized mice. Mice were recovered on a warming blanket at a 30-degree angle and euthanized at 4 hours after instillation.

Hyperoxia model. C57BL/6 WT and $c-m \mathrm{pl}^{-/-}$mice (C57BL/6 background) were placed in a sealed, plexiglass chamber, through which $100 \%$ oxygen was continuously flowing at $2-31 / \min$ (28). Oxygen saturations within the chamber were continuously monitored and maintained at more than $95 \%$ at all times. Mice were euthanized when they appeared moribund or at 96 hours.

Measurement of extravascular lung water and lung vascular permeability. Bloodless, extravascular lung water was measured as previously described (45, 46). Briefly, lungs were removed at the end of the experiment, weighed, homogenized, and placed in a drying oven for 24 hours. Measuring hemoglobin in the lung homogenate allowed for the calculation of bloodless extravascular lung water.

We measured lung vascular permeability to protein by instilling mice with i.v. ${ }^{125}$ I-labeled albumin (Iso-Tex Diagnostics Inc.). The ratio of the radioactivity as measured with a gamma counter (Packard 5000 Series) in the blood and the bloodless lung was used to calculate the lung extravascular plasma equivalents (EVPEs), as we have previously described $(46,47)$.

Bone marrow chimera experiments. As previously described, mice were lethally irradiated (6 Gy) and immediately reconstituted via retro-orbital injection with either WT or TLR4 ${ }^{d}$ bone marrow $\left(5 \times 10^{6}\right.$ cells $)(48)$. Mice 
were administered antibiotic-treated water for 3 weeks and then used for experiments at approximately 8 weeks after bone marrow transfer. Using this protocol, at 8 weeks after bone marrow transplantation, more than $90 \%$ of circulating hematopoietic cells are of donor origin.

Neutrophil and platelet depletion. Neutrophil depletion was accomplished with Gr-1 mAb (250 $\mu \mathrm{g}$, i.p.) delivered 24 hours prior to experiments (5). For the platelet depletion experiments, we used a rabbit, anti-mouse serum $(25 \mu \mathrm{g}$, i.v.) delivered 2 hours prior to the planned experiments (38). Control Abs (isotype control $\mathrm{mAb}$, normal rabbit serum) were used in both depletion protocols.

${ }^{51} \mathrm{Cr}$-labeled platelet experiments. ${ }^{51} \mathrm{Cr}$ labeling of platelets was performed as previously described $(38,49)$. Blood was collected into ACD-containing syringes, placed in PIPES buffer, and centrifuged at $85 \mathrm{~g}$ for $10 \mathrm{~min}$ utes. The platelet-rich plasma was then collected, Apyrase $(1 \mu / \mathrm{ml}$; SigmaAldrich) was added to inhibit platelet activation, and then the plasma was centrifuged at $657 \mathrm{~g}$ for 7 minutes. The platelet pellet was gently resuspended in Tyrodes buffer and $0.1 \mu \mathrm{Ci}$ of ${ }^{51} \mathrm{Cr}$ (MP Biomedicals Inc.) was added and gently mixed for 1 hour. The platelets were then washed in PBS and counted. Approximately $5 \times 10^{8}$ platelets were administered, via the jugular vein, to mice for the platelet trafficking studies. At the end of the experiment, the radioactivity in the whole lungs and a $100 \mu \mathrm{l}$ aliquot of whole blood were determined with a gamma counter.

MPO measurements. Lungs were homogenized on ice in hexadecyltrimethylammonium bromide (HDTA) buffer and centrifuged, and $10 \mu \mathrm{l}$ of the supernatant and MPO standard (Sigma-Aldrich) were aliquoted onto a 96-well plate. To each well, $200 \mu \mathrm{l}$ of $o$-Dianisidine solution and $10 \mu \mathrm{l}$ of $0.1 \% \mathrm{H}_{2} \mathrm{O}_{2}$ were added. The absorbance at $405 \mathrm{~nm}$ was read with a spectrophotometer after 5 minutes and expressed as units/ $\mathrm{ml}$ of lung supernatant using a standard curve.

$P$ selectin and MAC-1 experiments. P selectin $\mathrm{mAb}(30 \mu \mathrm{g})$ or isotype control $\mathrm{mAb}$ was delivered i.v. immediately prior to the acid ALI experiments. In the TRALI experiments, P selectin or isotype control $\mathrm{mAb}(30 \mu \mathrm{g})$ were delivered, both prior to LPS priming and immediately prior to MHC I $\mathrm{mAb}$ challenge. CD11b mAb (1 mg/kg), $\alpha-\mathrm{M} 2 \mathrm{Ab}(100 \mu \mathrm{g})$, or control Abs were given i.v. immediately prior to MHC I mAb.

Aspirin experiments. Aspirin tablets (ASA, $325 \mathrm{mg}$ ) were crushed, dissolved in DMSO $(100 \mathrm{mg} / \mathrm{ml})$, and diluted in PBS for i.p. injection. Aspirin $(100 \mu \mathrm{g} / \mathrm{g}$, i.p.) and vehicle control (DMSO) were delivered i.p. 30 minutes prior to LPS priming and again 2 hours prior to MHC I mAb challenge.

Flow cytometry. Peripheral blood was stained in the presence of Fc $\gamma$ RII/IIIblocking Ab (2.4G2), PE-conjugated Ly-6G (1A8), and APC-conjugated CD11b (M1/70). A biotinylation kit (Pierce) was used to produce $\mathrm{H} 2 \mathrm{~K}^{\mathrm{d}}$ biotin $\mathrm{mAb}$ from the 34-1-2S hybridoma. Anti-H2 $\mathrm{K}^{\mathrm{d}}$-biotin was detected using FITC-conjugated streptavidin (BD Biosciences - Pharmingen). Neutrophils were gated by appropriate forward- and side-scatter settings and Ly-6G and CD11b positivity. Flow cytometric acquisition was performed using a FACScan (BD Biosciences; Cytek Development Inc.), and data were analyzed using FlowJo Software (TreeStar).

Isolation of lung endothelial cells and quantitative PCR. Lung endothelial cells were isolated using standard methods (21). Briefly, mice were administered heparin (50 units, i.p.) and euthanized, and the lungs were perfused with $5 \%$ BSA. The lungs were removed, finely minced, incubated with col- lagenase A ( $1 \mathrm{mg} / \mathrm{ml}$; Sigma-Aldrich) at $37^{\circ} \mathrm{C}$ for 60 minutes with gentle shaking, and then filtered using a $100-\mu \mathrm{m}$ mesh filter. The cell suspension was incubated with rat, anti-mouse PECAM-1 Ab $(1.5 \mu \mathrm{g} / \mathrm{ml}$; BD Biosciences - Pharmingen) for 30 minutes at $4^{\circ} \mathrm{C}$, washed, and then incubated with sheep, anti-rat IgG magnetic beads (Dynabeads; Dyno) for 30 minutes at $4^{\circ} \mathrm{C}$. A magnetic column was used to positively select lung endothelial cells which were cleaved from the magnetic beads with trypsin $(0.05 \%)$. The cell pellet was resuspended in RLT buffer, and RNA was purified using the RNeasy Mini Kit (Qiagen). The RNA was DNase treated and reverse transcribed to cDNA (Bio-Rad) for quantitative PCR. Gene primer/probe sets (Tie-2, H2Kd, L19; Applied Biosystems) were used with TaqMan quantitative PCR to determine the percentage expression of the gene of interest relative to the control gene (L19). Only Tie-2-expressing samples were used in the analysis.

Histology and immunohistochemistry. For routine $\mathrm{H} \& \mathrm{E}$ and the Gr-1 mAb immunohistochemistry experiments, the lungs from euthanized mice were inflated with air, the trachea was ligated, and the lungs were removed and immersed in $4 \%$ paraformaldehyde for 24 hours. The lungs were then serially dehydrated in alcohol and embedded in paraffin. Sections $(5 \mu \mathrm{m})$ were used for routine $\mathrm{H} \& \mathrm{E}$ and $\mathrm{Gr}-1 \mathrm{mAb}$ immunohistochemistry. A biotinylated rabbit, anti-rat $\mathrm{Ab}$ (Vector) was used as the secondary $\mathrm{Ab}$ for the $\mathrm{Gr}-1$ $\mathrm{mAb}$ immunohistochemistry, and the samples were then processed with Vectastain ABC RTU reagent (Vector), DAB chromogen solution (Vector), and counterstained with Hematoxylin (Sigma-Aldrich).

For the CD41 immunohistochemistry, slides of mouse platelet-rich plasma (air dried) were used as a positive control. Paraffin-embedded sections did not yield any staining with our protocol. Frozen sections of mouse lung were prepared by removing the lungs and embedding them immediately in OCT, followed by slowly freezing the samples on dry ice. The frozen lungs were then sectioned $(10 \mu \mathrm{m})$, fixed in acetone $\left(4^{\circ} \mathrm{C}\right)$, blocked in $2.5 \%$ rabbit serum, and incubated with the primary $\mathrm{Ab}$ (rat, anti-mouse $\mathrm{CD} 41)$ at a 1:100 dilution. A rabbit, anti-rat secondary Ab (Vector) was added at 1:250 dilution, and the slides were processed as per the Gr-1 immunohistochemistry.

Statistics. Results are reported as both individual data points and mean \pm SD. To determine significance, 2-tailed Student's $t$ test, ANOVA, and Fisher's exact tests were used as appropriate (version 16.0; SPSS). $P$ values of less than or equal to 0.05 were considered to be statistically significant.

\section{Acknowledgments}

This work was supported in part by NIH grants HL082742 (to M.R. Looney), HL51854 (to M.A. Matthay), and HL081027 (to M.A. Matthay and C.A. Lowell) and research grants from the American Lung Association, American Thoracic Society, and National Blood Foundation (all to M.R. Looney).

Received for publication December 23, 2008, and accepted in revised form August 19, 2009.

Address correspondence to: Mark R. Looney, 513 Parnassus Avenue, San Francisco, California 94143-0130, USA. Phone: (415) 476-9190; Fax: (415) 502-2126; E-mail: mark.looney@ucsf.edu.
1. Toy, P., et al. 2005. Transfusion-related acute lung injury: definition and review. Crit. Care Med. 33:721-726.

2. Holness, L., Knippen, M.A., Simmons, L., and Lachenbruch, P.A. 2004. Fatalities caused by TRALI. Transfus. Med. Rev. 18:184-188.

3. Kopko, P.M., Marshall, C.S., MacKenzie, M.R., Holland, P.V., and Popovsky, M.A. 2002. Transfusion-related acute lung injury: report of a clinical look-back investigation. JAMA. 287:1968-1971.

4. Looney, M.R., Gropper, M.A., and Matthay, M.A 2004. Transfusion-related acute lung injury: a review. Chest. 126:249-258.

5. Looney, M.R., Su, X., Van Ziffle, J.A., Lowell, C.A., and Matthay, M.A. 2006. Neutrophils and their Fc gamma receptors are essential in a mouse model of transfusion-related acute lung injury. J. Clin. Invest. 116:1615-1623.
6. Gajic, O., et al. 2007. Transfusion from male-only versus female donors in critically ill recipients of high plasma volume components. Crit. Care Med. 35:1645-1648.

7. Palfi, M., Berg, S., Ernerudh, J., and Berlin, G. 2001. A randomized controlled trial oftransfusion-related acute lung injury: is plasma from multiparous blood donors dangerous? Transfusion. 41:317-322.

8. Gajic, O., et al. 2007. Transfusion-related acute 
lung injury in the critically ill: prospective nested case-control study. Am. J. Respir. Crit. Care Med. 176:886-891.

9. Silliman, C.C., et al. 1997. The association of biologically active lipids with the development of transfusion-related acute lung injury: a retrospective study. Transfusion. 37:719-726.

10. Silliman, C.C., et al. 2003. Transfusion-related acute lung injury: epidemiology and a prospective analysis of etiologic factors. Blood. 101:454-462.

11. Toy, P., Hollis-Perry, K.M., Jun, J., and Nakagawa, M. 2004. Recipients of blood from a donor with multiple HLA antibodies: a lookback study of transfusion-related acute lung injury. Transfusion. 44:1683-1688.

12. Muniz, M., et al. 2008. Patient-specific transfusionrelated acute lung injury. Vox Sang. 94:70-73.

13. Bux, J., and Sachs, U.J. 2007. The pathogenesis of transfusion-related acute lung injury (TRALI). Br. J. Haematol. 136:788-799.

14. Silliman, C.C., et al. 1998. Plasma and lipids from stored packed red blood cells cause acute lung injury in an animal model. J. Clin. Invest. 101:1458-1467.

15. Silliman, C.C., et al. 2003. Plasma and lipids from stored platelets cause acute lung injury in an animal model. Transfusion. 43:633-640.

16. Wyman, T.H., et al. 2002. A two-insult in vitro model of PMN-mediated pulmonary endothelial damage: requirements for adherence and chemokine release. Am. J. Physiol. Cell Physiol. 283:C1592-C1603.

17. Godzich, M., et al. 2006. Activation of the stress protein response prevents the development of pulmonary edema by inhibiting VEGF cell signaling in a model of lung ischemia-reperfusion injury in rats. FASEB J. 20:1519-1521.

18. Frank, J.A., et al. 2002. Low tidal volume reduces epithelial and endothelial injury in acid-injured rat lungs. Am. J. Respir. Crit. Care Med. 165:242-249.

19. Altemeier, W.A., et al. 2005. Modulation of lipopolysaccharide-induced gene transcription and promotion of lung injury by mechanical ventilation. J. Immunol. 175:3369-3376.

20. Zarbock, A., Singbartl, K., and Ley, K. 2006. Complete reversal of acid-induced acute lung injury by blocking of platelet-neutrophil aggregation. J. Clin. Invest. 116:3211-3219.

21. Tiruppathi, C., et al. 2002. Impairment of storeoperated Ca2+ entry in TRPC4(-/-) mice interferes with increase in lung microvascular permeability. Circ. Res. 91:70-76.

22. Yomtovian, R., et al. 1984. Severe pulmonary hypersensitivity associated with passive transfusion of a neutrophil-specific antibody. Lancet. 1:244-246.

23. Leger, R., Palm, S., Wulf, H., Vosberg, A., and Neppert, J. 1999. Transfusion-related lung injury with leukopenic reaction caused by fresh frozen plasma containing anti-NB1. Anesthesiology. 91:1529-1532.

24. Ausley, M.B., Jr. 1987. Fatal transfusion reactions caused by donor antibodies to recipient leukocytes. Am. J. Forensic Med. Pathol. 8:287-290.

25. Su, X., et al. 2007. Activation of the alpha7 nAChR reduces acid-induced acute lung injury in mice and rats. Am. J. Respir. Cell Mol. Biol. 37:186-192.

26. Alexander, W.S., Roberts, A.W., Nicola, N.A., Li, R., and Metcalf, D. 1996. Deficiencies in progenitor cells of multiple hematopoietic lineages and defective megakaryocytopoiesis in mice lacking the thrombopoietic receptor c-Mpl. Blood. 87:2162-2170.

27. Perkowski, S., et al. 2006. Dissociation between alveolar transmigration of neutrophils and lung injury in hyperoxia. Am. J. Physiol. Lung Cell Mol. Physiol. 291:L1050-L1058.

28. Looney, M.R., Esmon, C.T., and Matthay, M.A. 2009. Role of coagulation pathways and treatment with activated protein $C$ in hyperoxic lung injury. Thorax. 64:114-120.

29. Moore, K.L., et al. 1992. Identification of a specific glycoprotein ligand for P-selectin (CD62) on myeloid cells. J. Cell Biol. 118:445-456.

30. McEver, R.P., and Cummings, R.D. 1997. Perspectives series: cell adhesion in vascular biology. Role of PSGL-1 binding to selectins in leukocyte recruitment. J. Clin. Invest. 100:485-491.

31. Simon, D.I., et al. 2000. Platelet glycoprotein ibalpha is a counterreceptor for the leukocyte integrin Mac-1 (CD11b/CD18). J. Exp. Med. 192:193-204.

32. Wang, Y., et al. 2005. Leukocyte engagement of platelet glycoprotein Ibalpha via the integrin Mac1 is critical for the biological response to vascular injury. Circulation. 112:2993-3000.

33. Pluskota, E., et al. 2008. Expression, activation, and function of integrin alphaMbeta2 (Mac-1) on neutrophil-derived microparticles. Blood. 112:2327-2335.

34. Weber, C., and Springer, T.A. 1997. Neutrophil accumulation on activated, surface-adherent platelets in flow is mediated by interaction of Mac-1 with fibrinogen bound to alphaIIbbeta3 and stimulated by platelet-activating factor. J. Clin. Invest. 100:2085-2093.

35. Fukunaga, K., Kohli, P., Bonnans, C., Fredenburgh, L.E., and Levy, B.D. 2005. Cyclooxygenase 2 plays a pivotal role in the resolution of acute lung injury. J. Immunol. 174:5033-5039.

36. Nakagawa, M., and Toy, P. 2004. Acute and tran- sient decrease in neutrophil count in transfusionrelated acute lung injury: cases at one hospital. Transfusion. 44:1689-1694.

37. Andonegui, G., et al. 2003. Endothelium-derived Toll-like receptor- 4 is the key molecule in LPSinduced neutrophil sequestration into lungs. J. Clin. Invest. 111:1011-1020.

38. Andonegui, G., et al. 2005. Platelets express functional Toll-like receptor-4. Blood. 106:2417-2423.

39. Schneider, R.C., Zapol, W.M., and Carvalho, A.C. 1980. Platelet consumption and sequestration in severe acute respiratory failure. Am. Rev. Respir. Dis. 122:445-451.

40. Khan, S.Y., et al. 2006. Soluble CD40 ligand accumulates in stored blood components, primes neutrophils through CD40, and is a potential cofactor in the development of transfusion-related acute lung injury. Blood. 108:2455-2462.

41. Laufe, M.D., Simon, R.H., Flint, A., and Keller, J.B. 1986. Adult respiratory distress syndrome in neutropenic patients. Am. J. Med. 80:1022-1026.

42. Ognibene, F.P., et al. 1986. Adult respiratory distress syndrome in patients with severe neutropenia. N. Engl. J. Med. 315:547-551.

43. Rubenfeld, G.D., et al. 2005. Incidence and outcomes of acute lung injury. N. Engl. J. Med. 353:1685-1693.

44. Su, X., Looney, M., Robriquet, L., Fang, X., and Matthay, M.A. 2004. Direct visual instillation as a method for efficient delivery of fluid into the distal airspaces of anesthetized mice. Exp. Lung Res. 30:479-483.

45. Pittet, J.F., et al. 1994. Stimulation of lung epithelial liquid clearance by endogenous release of catecholamines in septic shock in anesthetized rats. J. Clin. Invest. 94:663-671.

46. Wiener-Kronish, J.P., Albertine, K.H., and Matthay, M.A. 1991. Differential responses of the endothelial and epithelial barriers of the lung in sheep to Escherichia coli endotoxin. J. Clin. Invest. 88:864-875.

47. Folkesson, H.G., Matthay, M.A., Hebert, C.A., and Broaddus, V.C. 1995. Acid aspiration-induced lung injury in rabbits is mediated by interleukin-8dependent mechanisms. J. Clin. Invest. 96:107-116.

48. Mocsai, A., Zhou, M., Meng, F., Tybulewicz, V.L., and Lowell, C.A. 2002. Syk is required for integrin signaling in neutrophils. Immunity. 16:547-558.

49. Barazzone, C., Tacchini-Cottier, F., Vesin, C., Rochat, A.F., and Piguet, P.F. 1996. Hyperoxia induces platelet activation and lung sequestration: an event dependent on tumor necrosis factor-alpha and CD11a. Am. J. Respir. Cell Mol. Biol. 15:107-114. 